\title{
Public Private Partnerships and Next Generation Networks
}

\author{
Idongesit Williams and Morten Falch \\ CMI, Aalborg University, Copenhagen, Denmark \\ idong@plan.aau.dk, falch@cmi.aau.dk
}

\begin{abstract}
This section discusses the possible role of Public Private Partnership (PPP) in the development of infrastructure for Next Generation Networks. The focus is on the developing countries perspective. Case studies describe the African approach in using PPP to fund telecom infrastructure development in rural areas.
\end{abstract}

Keywords: Public Private Partnership, Next Generation Networks, Governance, Universal Access, Developing country.

\section{Introduction}

As Information and Communications Technologies move towards Next Generation Networks (NGNs), broadband has moved from "just one of those telecommunication network technologies" to a national resource as identified by the secretary general of the ITU [19]. This has heightened the attention of Governments and other policy bodies on the potentials of broadband technology to the economy, as well as the social lives of their citizens. Governments around the world are looking for efficient ways for partnering with the private sector to develop broadband and attain their universal service objectives as well. Hence in the development of NGNs, various forms of Public Private Partnerships (PPP) will play an important role in the development of Next Generation Access (NGA) infrastructure. PPP may not necessarily be implemented as it is today, but the market situation and the socio-economic realities that may act as an impediment to an effective working of the market in certain areas will justify the use of PPP to initiate a market based development.

Still more capacity can be offered by wireless services and wireless network solutions are becoming viable alternatives to wired network infrastructures. This has led to a reduction in costs of diffusion and adoption of ICTs. Still there will be some remote areas, which are difficult to reach, and where provision of broadband connectivity will remain unprofitable from a commercial point of view. Here PPP can be deployed in order to extend connectivity to these remote areas also. Especially in developing countries this is a pertinent problem. Here, rural areas are often poorly equipped with infrastructure facilities and the customer base is weak due to low income levels and a sparse population. This section of the book takes a look at some of the current PPP approaches towards development of broadband and other network services, and discusses how these can be applied in sub-Saharan Africa. 


\section{The Concept of PPP}

There are many different definitions of the concept of PPP. PPP has been described as "a cooperative venture between the public and the private sectors built on the expertise of each partner, that best meets clearly defined public needs through the appropriation of resources risks and awards" (CCPPP). This cooperation, of course, varies in its financial, organizational and implementation design. According to the EU Green Paper on Public Private Partnership [2], the private actors should do the implementation, must take part in the funding and should assume at least a part of the financial risk, while it is up to the public actor to define objectives and monitoring.

For a number of years, PPP was seen as a way to involve private companies in publicly initiated activities [15]. This could, for instance, be outsourcing of care for the elderly to private businesses operating under public supervision or licenses. The liberalization of telecommunications can also, to some extent, be seen in this view with commercial operators guided by public policy demands on the sector with respect to universal service requirements and price regulations. However, the present discourse on PPP in the telecommunications area is turning the other way round. Now, the issue is the involvement of public money in providing rural access to privately owned broadband infrastructure [4].

This has led to the present discourse on PPP in the telecommunications where public money is being spent as a cushion to private financing in order to help the private sector achieve the universal access objectives set by public authorities. This new financing option has not in any way affected the initial PPP objectives from both parties. Each party expects trust, openness, fairness and mutual respect from the other party [10]. The expectations of the two parties remain the same even as the financing options and spectrum of PPP possibilities continue to evolve. The public agency expects an improvement in program performance, cost efficiencies, better provision of services and appropriate allocation of risks and responsibilities [14]. The private sector expects a better investment potential that will lead to reasonable profits. This will in turn open opportunities for them to expand their businesses [17]. However, this new push by the public in some cases has led to the development of a new spectrum of concepts of PPP. The implementation of PPP may take different avenues but the basic idea of cooperation between the public and private sector remain the same irrespective of how the financial obligations are designed.

There are other ways in which public telecommunication agencies can fund Universal Access and Service of NGNs. These will continue to be used of course to fund infrastructure development of NGNs as identified by [3]. Some of them are:

- Universal Assess and Service funds (UASF)

- Public funding programs and investments

- Investment by private companies other than telecom operators

- Funding through Non-Profit Organizations

However, PPP has some advantages that make the concept appealing and beneficial to the development of NGN infrastructure in Sub-Saharan Africa and rural areas in the 
world. These includes, access to private finance for expanding services, clearer objectives, new ideas, flexibility, better planning, improved incentives for competitive tendering and greater value for money for public projects [13], [18].

Secondly, the four funding mechanisms listed above can be implemented via the vehicle of PPP. In Africa and many other parts of the world, UASFs provide subsidies to private companies for the development of telecommunication infrastructure in rural areas, underserved and non-served areas. There are such cases in Uganda, Mozambique, and a host of other African countries [8], [9]. In the case of Uganda, the USAF gets money from the World Bank and provides this money as seed capitals, a form of subsidy to the private sector to develop Universal Access projects. Public funded programs and investments can be a PPP if private sector is also contributing some form of capital to the project and investment by private companies can also be a PPP if a public agency is involved in some way as a collaborating partner in the project. Funding through NGO's may be a PPP if the NGO is either a public NGO or the NGO is partnering with some public agency to deliver the telecommunication infrastructure development.

The ability of PPP to be used in different ways makes it an interesting way of funding next generation networks in Africa, rural areas, non-served and underserved countries of the world.

\section{Case Studies}

So far, as a result of the problem of accessing remote and difficult to reach places, some countries are taking practical steps to develop a partnership with the private sector in the development of broadband infrastructure in these remote areas. Different forms of PPP financing options for telecommunication and other infrastructure all around the world include the Build-Operate-Transfer (BOT), Build-Transfer-Operate (BTO), Build-Own-Operate (BOO), Build-Own-Operate-Transfer (BOOT), BuildLease-Transfer (BLT), Design-Build-Finance-Operate (DBFO) and Design Construct Manage Finance (DCMF) concepts. Most of these public-financing cases are very remote in the African telecommunication scene. Most of Africa embraced privatization and semi-privatization schemes during the liberalization era. However in other sectors of the economy in Africa like transportation etc., these forms of PPP have been used.

It is pertinent to point out that PPP today is regarded as a complement to a free market in the development of broadband infrastructure and the market. There will likely be fewer interventions in the development of Next Generation Access Networks in cities, metropolitan areas and commercially viable areas. As the family of fixed and mobile standards of Next Generation Networks mature, this will go a long way in enabling the diffusion and adoption of these services en masse. However, this maturity will not occur without the right business models and governance structures put in place by players in the next generation value chain and the public regulating bodies respectively. 
It is still difficult beforehand to tell if a competition driven market alone will enable the desired objectives of universal access to the Next Generation Networks in a specific area, or if a PPP program will be an efficient way to achieve the desired policy objectives.

In Africa, the use of PPP to deploy infrastructure and thereby propping the market to spring up in the telecommunications sector can be seen in the user adoption side, the infrastructure development and Internet service development. NGNs are largely envisaged to be delivered via broadband (fixed and mobile) and IP networks. The infrastructure of these new networks may be cheaper or more expensive than the existing family of technologies. However, the approach of using PPP as a compliment to market mechanisms will likely continue as long as there are rural areas in Africa.

The four case studies below illustrate that various forms of PPP have been developed as a compliment to the competition fostered by liberalization, which gave way to privatization and open access of telecommunication service delivery and infrastructure. This has taken place at the continental and the national levels as well as at the regional level.

\subsection{NEPAD Broadband Connectivity Programme - Continental Fiber Optics Deployment}

In the African continent, there has been an ambitious move by New Partnership for African Development (NEPAD) to provide broadband connectivity in all the 54 African countries [12]. Basically, one might say Africa is getting ready for NGNs. The aim is to provide abundant bandwidth with easier connectivity at a reduced cost. All NEPAD head of states, which invariably are all the heads of States in Africa adopted the proposal, however not every country that is signatory to the project have embarked on proactive steps to ensure the possibility of this project. The development is divided into two areas, the NEPAD ICT broadband infrastructure network for Eastern and Southern Africa and the NEPAD ICT broadband infrastructure network for Central, West, and North Africa.

The Policy Principles developed for this project clearly point to the complementary role of PPP in relation to market development:

1. Non-discriminatory Open Access, whereby all Authorized Service Providers, in any country market, will access broadband connectivity on the same terms, including pricing. This will provide a level playing field for all Authorized Service Providers, increase competition, and thereby reduce bandwidth prices to the endusers.

2. Equitable Joint Ownership of the backbone infrastructure across the region.

3. Use of Special Purpose Vehicles (SPVs) to build, own and operate the Broadband ICT network

4. The Basic ICT Broadband Infrastructure should be viewed as a "public good".

5. Application of PPP in the development of the network. 
Policies here as agreed by the policy makers covered both deployment of submarine cables as well as terrestrial networks [12]. NEPAD is the Public Agency involved in this project and the Special Purpose Vehicle is a private consortium involved in the project.

The concept of the Special Purpose Vehicle is encapsulated in the Kigali Protocol which encapsulates the policy principle listed above as well. The Special Purpose Vehicle owns, operate and maintain the broadband Network. The NEPAD submarine SPV are to be set up by African Telco and non-telecom investor. The African Investors have a stake of $45 \%$ while the International investors will have $25 \%$. Funding for the PPP for the Broadband infrastructure Network for Eastern and Southern Africa were expected from international donors like Industrial Development Corporation (IDC), Development bank of Southern Africa (DBSA) and Pan African Infrastructure Development Fund (PAIDF).

This project is still being developed at the moment, but it gives a clear indication of the regional approach to the present broadband. This may be extended to the future towards next generation networks depending on the infrastructure needs. Other initiatives in the same area are GLO [6] and, SAT-3/WACS/SAFE [16].

\subsection{PPP and User Adoption - Rwanda Mobile Telephone Adoption Scheme}

In order to attract less affluent Africans, different African governments have taken some regulatory and PPP steps in addressing the problem. One of the major problems experienced in Africa was the affordability of mobile telephony handsets. This problem is likely to also continue into the Next Generation Network era of telecommunication networks. Hence various forms of PPP as well as regulation may still be relevant in propping demand for next generation networks by ensuring the affordability of Customer Premises Equipment (CPE).

On the supply side, marketing innovations played a major role in promoting the competition enabled by the liberalization. These innovations from the supply side triggered the adoption of ICT on the demand side. A clear example is mobile telephony. Mobile telephony, which has become a success in the region, was enabled by the introduction of the pre-paid mobile solutions as well as per-second billing in call termination charges. These drivers made mobile telephony attractive to the less affluent African who could now own a mobile telephone without the fear of incurring monthly charges in which the subscriber had to pay later as in the case of postpaid solutions. However, despite these successes, there were still issues of the high cost of mobile telephony handsets. Many governments had to intervene by the reduction of taxation as in the case of Ghana [11] and the use of subsidies to enable less affluent citizens acquire mobile telephony handsets as in the case of Rwanda. What makes the case of Rwanda unique is the partnership between the Government of Rwanda, MTN (a telecommunication operator) and the Rwanda Development Bank (BRD) [1]. 


\subsection{PPP and Infrastructure Development - Uganda USAF Funding on Mobile Telephony Infrastructure}

The liberalization brought in either full or partial privatization of incumbent monopolies. However Uganda has a good case where competition was used alongside a PPP effort in the development of telecommunication infrastructure in rural areas. A case study conducted by Econone paints the following scenario.

The liberalization of the Ugandan telecommunication sector in 1993 led to the entrance of two new operators in addition to the later partially privatized incumbent, Uganda Telecommunications Limited (UTL). MTN was licensed as the Second National Operator in 1998 and Celtel were licensed to operate in the south west of the country. MTN and UTL were required to provide full country coverage. However despite regulatory measures to ensure the universal access obligation granted to MTN and UTL, the Government established a body called the Rural Communications Development Fund in 2001. The fund is financed by the payment of $1 \%$ of gross revenue from the three operators. The policy specifies the provision of basic communication services to all sub-counties with at least 5000 inhabitants by the year 2005. Licenses are granted by the Uganda Communications Commission (UCC) to independent local operators in areas most difficult to serve. The financing plan was to grant subsidy assistance of US\$1 for every US\$1 of private investment in the ICT infrastructure. Financial institutions like the World Bank estimated that US\$5.8 million of subsidy would be required to make the 2005 date feasible. The PPP in addition to the competitive market made possible the tele-density of Uganda to grow from 2 subscribers per 1000 people in 1998 to 32 subscribers per 1000 inhabitants in 2003 [5].

Other supporting examples: In Ghana, the Universal Access and Service Funds GIFEC is also engaging the PPP as a way of Common Telecommunications Sites facilities across Ghana. They collaborate with telecommunication companies in the award of Subsidies to telecommunication companies who are willing to develop infrastructure for co-location [7]. In Nigeria, The Universal Service Provision Fund provides subsidy to the building of GSM Base Transceiver Stations (BTS). There is a similar approach by the Nigerian Universal Access and service fund in delivering wholesale internet bandwidth to Community Communication Centers (CCC), Cybercafés, rural internet service providers etc. The essence of this PPP effort in Nigeria is to enable private operators to provide and operate broadband network in rural areas [20].

\subsection{Internet Service Deployment - Egyptian Smart Village Project}

In 2005 the Egyptian government embarked on the 'smart village' initiative concept. This project is a PPP between the Ministry of Information and Communication Technology (MCIT) and a private consortium. The MCIT provided 300 acres of land (20\% of the cost) and the private investors financed the remaining $80 \%$. Infrastructure provided in the 'smart village' is fiber optic network and a multi-source power supply. A related project is the free internet initiative. The aim of this project 
was to enable users across Egypt to access Internet at the cost of a local call with no additional subscription fee. The free internet initiative is based on an offloading/revenue sharing model. The Internet Service Providers (ISP) are allowed to co-locate their access equipment at telecom Egypt local exchanges and re-routed to the ISP data backbone. This resulted in the major offloading of the Telecom Egypt PSTN network. Revenue accrued was shared between telecom Egypt and service providers [9].

\section{Conclusions}

The realities of the deployment of NGNs in developed and developing countries will differ greatly depending on the approaches as seen in the cases stated. These approaches will depend on the economic realities of the country, the priority placed on the development of ICT over other more important economic needs, political will and the effects of globalization. These factors will play a crucial role in the public intervention of deploying NGNs.

At the moment, developing countries in Africa are yet to achieve their universal access targets on previous standards in contrast to their counterparts in the EU. The same can be said about some countries in Asia. Hence with these shortfalls, the same way the governments of developing countries saw the need to engage in PPP to compliment and enable competition of existing standards, this same approach will still be adopted and redefined over time using different approaches to reach areas where connectivity is still a challenge. PPP will enable network operators deploy NGNs at a cheaper cost than they would if they carried the burden all by themselves. The Governments may not necessarily provide subsidies, but they may provide incentive regulations or even adopt the various forms of PPP as a way of either sharing or lessening cost. As pointed out in the case of Rwanda, governments may still use PPP to reduce the cost of acquiring the NGN services. Although it is difficult to foresee the future, the relevance of PPP as a public intervention tool in the deployment of NGNs in the future can't be ruled out.

Open Access. This article is distributed under the terms of the Creative Commons Attribution Noncommercial License which permits any noncommercial use, distribution, and reproduction in any medium, provided the original author(s) and source are credited.

\section{References}

1. Balancing Act (November 2011), http://www.balancingact-africa.com/ news/en/issue-no-390/telecoms/rwanda-s-government/en

2. Canadian Council for Public-Private partnerships (CCPPP), Available on the internet (November 2, 2011),

http://www.pppcouncil.ca/aboutPPP_definition.asp.cited

3. European Commission. Green Paper on Public-Private Partnerships and Community Law on Public Contracts and Concessions. COM(2004) 327 final (2004) 
4. Falch, M., Henten, A.: Investment dimensions in a Universal Service Perspective: Next Generation Networks, alternative funding mechanisms and Public-Private Partnerships. Info. 10(5/6), 33-45 (2008)

5. Falch, M., Henten, A.: Public Private Partnerships as tool for stimulating investment in broadband. Telecommunications Policy 34(9), 496-504 (2010)

6. Farlem, P.: Working together, Accessing Public-Private partnerships in Africa. OECD (2005), http: //www. oecd.org/dataoecd/44/4/34867724.pdf (November 2011)

7. GLO1. (November 2011), http: / /www . gloworld. com/glo1.asp

8. GIFEC. (November 2011), http://gifec.gov.gh/index.php?option= com_content\&view=articlesid=77: telecommunicationoperators\&catid=38: projects\&Itemid $=248$

9. ICT regulation toolkit. Public Private Partnerships (November 2011), http://www. ictregulationtoolkit.org/en/Section.3288.html

10. ICT. regulation toolkit. Public-Private Partnerships in the telecommunications and ICT sector (November 2011), http://www.ictregulationtoolkit.org/en/ PracticeNote. 3160. html

11. Jamali, D.: Success and failure mechanisms of Public Private Partnerships (PPPs) in developing countries. Insights from the Lebanese context. The International Journal of Public Sector Management 17(5), 414-430 (2004)

12. Klutse, F.: Mobile Phones now chapter in Ghana. IT Africa news (2008), http: / /www. itnewsafrica.com/2008/09/mobile-phones-nowcheaper-in-ghana (November 2011)

13. NEPAD East African Commission (November 2011), http: / / www . eafricacommission.org/projects/126/nepad-ictbroadband-infrastructure-network

14. Nijkamp, P., Van der Burch, M., Vidigni, G.: A comparative institutional evaluation of public private partnerships in Dutch urban land - use and revitalization projects. Urban studies 39(10), 1865-1880 (2002)

15. Pongsiri, N.: Regulation and Public Private Partnerships. The International Journal of Public Sector Management 15(6), 487-495 (2002)

16. Sadka, E.: Public-Private Partnerships: A Public Economics Perspective. IMF Working Paper, WP/06/77 (2006)

17. SAT-3/WASC/SAFE (November 2011), http: / / www . safe-sat3 . co . za/

18. Scharle, P.: Public Private Partnership as a social game. Innovation 15(3), 227-252 (2002)

19. Spackman, M.: Public Private Partnerships: lessons from the British approach. Economic Systems 26, 283-301 (2002)

20. Toure, H.: Building our Networked Future based on Broadband. ITU (2010), http: / /www. itu.int/en/broadband/pages/overview.aspx

21. Universal Service Provision Fund. Universal Service Provision Annual Report 2009. Nigerian Communications Commission (2009) http://uspf.gov.ng/downloads.htm?p13_sectionid=2 